\title{
LA MASONERÍA Y LA SEGUNDA REPÚBLICA ESPAÑOLA (1931-1939)
}

\author{
Cayetano Núñez Rivero \\ doi: http://dx.doi.org/10.18543/ed-65(1)-2017pp243-270
}

\begin{abstract}
SUMARIO: 1. CONSIDERACIONES PREVIAS. 2. LOS VALORES Y PRINCIPIOS MASÓNICOS Y LOS VALORES Y PRINCIPIOS REPUBLICANOS. 3. LA MASONERÍA, ¿SUJETO ACTIVO O PASIVO DE LAS LEYES REPUBLICANAS? 4. A MODO DE CONCLUSIÓN.
\end{abstract}

\section{CONSIDERACIONES PREVIAS}

Se ha sostenido por numerosos autores que el paso del sistema monárquico al republicano y el proceso constituyente del mismo son coincidentes con el denominado periodo de oro de la masonería española, afirmación que se sostiene en la influencia que la institución masónica tuvo a través de sus miembros más destacados en la configuración del nuevo régimen.

Sin embargo esta afirmación debe ser matizada en los siguientes aspectos:

1. Es cierto que el número de masones presentes en las Cortes republicanas, especialmente en el periodo constituyente es muy elevado, representando aproximadamente un 38 por ciento del total de representantes parlamentarios, así como el número de Presidentes del Consejo de Ministros masones: Manuel Azaña (1931 a 1933: 1936); Alejandro Lerroux (1933-1934-35); Diego Martínez Barrio (1933-1936); Ricardo Samper Ibáñez (1934); Manuel Portela Valladares (1935-36); Santiago Casares Quiroga (1936); Augusto Barcía Trelles (1936); José Giralt Pereira (1936). A ello debemos añadir un gran número de ministros y altos funcionarios. Sin embargo, debe tenerse en cuenta que muchos de 
estos miembros de la Orden eran de muy reciente afiliación, siendo su actividad estrictamente masónica muy reducida; a este respecto, debemos considerar que durante el periodo de la Dictadura del General Primo de Rivera, en virtud de la represión sostenida por el régimen sobre los partidos políticos democráticos, muchos de sus miembros se cobijaron en las logias masónicas, donde pudieron encontrar un espacio de tolerancia para sus reuniones, aunque en este caso no tuvieran el carácter de partidarias, lo que en modo alguno supone que pueda sostenerse que la masonería tuviera una vida fácil durante el Directorio militar, ya que aunque su actividad fuera consentida por los poderes públicos, muchos de sus miembros acabaron en prisión, aunque ello fuera debido fundamentalmente a sus posiciones políticas y no estrictamente a su actividad masónica.

2. Los masones que mantienen una actividad destacada en la vida política republicana están adscritos a diferentes obediencias masónicas, tales como el Gran Oriente de España, (mayoritaria) la Gran Logia Española, Gran Logia Unida, el Gran Consejo Federal Simbólico, así como otras de menor relevancia y número de miembros, que en algunos casos mantienen entre sí un cierto grado de conflictividad que de alguna forma podía impedir la asunción de posturas comunes.

3. Los masones presentes en las Cortes constituyentes no pertenecían al mismo partido político, sino que formaban parte de casi todo el espectro parlamentario, con la excepción completa del grupo vasco-navarro y de la mayor parte de los restantes partidos de la derecha, aunque en este último caso dicha afirmación no pueda sostenerse en términos absolutos, de tal forma, que su presencia se ubicaba fundamentalmente en el centro republicano y los partidos de la izquierda, cuya variedad ideológica era muy amplia, como se revelaría en todo el proceso constituyente.

A lo anteriormente indicado debe añadirse que uno de los principios de la Masonería universal es el de que la institución, como tal no puede inmiscuirse en cuestiones políticas o religiosas y que su actuación debe ser respetuosa con la legislación del Estado donde desarrolle sus actividades, lo que no obsta, para que los masones concebidos individualmente puedan sostener las opiniones y desarrollar las actividades políticas como ciudadanos que consideren pertinentes.

Por otra parte, si medimos la importancia de la masonería española por el número de miembros de la organización y las logias u organizaciones masónicas existentes durante el periodo republicano, y especialmente en el proceso constituyente, éste es de carácter reducido, mostrando un carácter ascendente desde 1931 -proclamación de la República- hasta 1933 -triunfo 
electoral de la derecha-, que marca el inicio de un proceso descendente ${ }^{1}$. Orozco, el autor citado en nota precedente, aporta el siguiente cuadro:

\begin{tabular}{|c|c|c|c|c|c|c|}
\hline Año & $\mathbf{1 9 3 1}$ & $\mathbf{1 9 3 2}$ & $\mathbf{1 9 3 3}$ & $\mathbf{1 9 3 4}$ & $\mathbf{1 9 3 5}$ & $\mathbf{1 9 3 6}$ \\
\hline N. $^{\text {o de talleres }}$ & 141 & 183 & 220 & 200 & 191 & 172 \\
\hline
\end{tabular}

Respecto al número de miembros totales de las diferentes obediencias masónicas, sin que sea objeto de este trabajo precisar el número exacto de los mismos, en virtud de la pluralidad de fuentes, a veces contradictorias sobre este punto, y el número máximo que podemos manejar al respecto, sí podemos señalar que no pasaron de 7.000 para todo el periodo republicano y debemos considerar como de suma importancia que dicho número se refiere al total de personas que pertenecieron a la Orden, lo que no implica que tuvieran actividad masónica coincidente.

Los datos indicados anteriormente, obviamente se contradicen con la profusa documentación existente en el Archivo de Salamanca, donde encontramos registro de cerca de 48.000 fichas referentes a expedientes y procesos incoados a masones, pero a este respecto, debe señalarse, que a pesar de que dicho archivo es posiblemente el más completo que existe en el mundo sobre la actividad masónica, no es un archivo de la Masonería, sino sobre la Masonería y que tiene como fin la represión de la institución ${ }^{2}$, de tal forma, que junto a datos fidedignos de pertenencia de personas a la Masonería y de órganos de la misma, incluye referencias a otras, que fueron acusadas de ello, sin que dicha afirmación pudiera sostenerse de forma mínimamente sustentable, ya que dicha acusación, tanto durante la guerra civil como en el periodo posterior se utilizó por los Tribunales del Régimen militar para la condena de numerosos republicanos, pertenecieran o no a la Orden Masónica, práctica que tampoco era novedosa en la historia española, valga recordar al respecto la represión llevada a cabo por el Tribunal de la Inquisición que había sido restaurado en 1815, contra liberales constitucionalistas y bonapartistas acusados de su pertenencia no probada siempre a la masonería.

Así mismo, debe indicarse que existe una dificultad añadida para la identificación de personas pertenecientes a la orden masónica, pues en muchos

${ }^{1}$ Sobre las numerosas fuentes que pueden consultarse, nos remitimos al completo trabajo sobre este punto José Ignacio DE CRUZ OrOzCO, «Avance del mapa masónico de España durante la II República» en La masonería en la España del siglo XIX (Consejería de Educación y Cultura, 1987), 911-936.

${ }^{2}$ El 20 de abril de 1937 se creó la OIPA, para la represión de actividades marxistas y masónicas, y el 26 de abril de 1938 el archivo específico que quedaría radicado en Salamanca. 
casos utilizaban nombres simbólicos, y aunque en la mayoría de los casos es fácil encontrar la correlación de éstos, en otros, generalmente afiliados de menor relevancia, no. Por otra parte, no siempre los archivos de Logias fueron incautados por la policía franquista, ya que muchos fueron destruidos por los miembros de estas organizaciones o acompañaron al exilio a los masones que pudieron salir del país; valga como ejemplo la manifestación contenida en la página informativa del Supremo Consejo del grado 33 y último del Rito Escocés Antiguo y Aceptado para España ${ }^{3}$, «(...) los archivos del Supremo Consejo se perdieron o fueran destruidos voluntariamente, para evitar que la dictadura del General Franco se apoderase de ellos, con las consecuencias presumibles. Parte de los archivos fueron trasladados a París y posteriormente otra vez destruidos, para impedir que las tropas de otra dictadura (los dictadores no gustan de la Masonería porque huele demasiado a Libertad), se incautaran de ellos...».

Es por ello, que al afrontar el estudio de la influencia de la masonería o de la propia historia de la institución en España, debemos tener en cuenta las palabras de Miguel Morayta ${ }^{4}$ pronunciadas hace ahora un siglo, referentes a la historia de la Masonería española, "La historia interna de la Masonería Española, no se ha escrito aún y seguramente no se escribirá nunca; faltan y faltarán siempre los documentos del caso necesario. Durante muchos años las logias no extendieron actas de sus tenidas, ni firmaron siquiera expedientes de iniciación, se hacía indispensable no dejar rastros de sus actos. ¿Cómo, sin escribir archivos, narrar las vicisitudes de la Orden? Mas hacedero, si bien no del todo fácil, es historiar sus manifestaciones externas, sus actos públicos, es decir sus trabajos intentados o cumplidos en el mundo profano» ${ }^{5}$.

\section{LOS VALORES Y PRINCIPIOS MASÓNICOS Y LOS VALORES Y PRINCIPIOS REPUBLICANOS}

De lo expuesto en el epígrafe anterior se desprende que esta exposición no se centrará en la influencia directa de las organizaciones masónicas en la actividad política durante el régimen republicano, al menos en lo que se

${ }^{3}$ www.scg33esp.org/.24/01/2015.

${ }^{4}$ Miguel Morayta Sagrario fue Soberano Gran Comendador del Supremo Consejo del grado 33 y último del rito Escocés, Antiguo y Aceptado para España, durante el periodo 1889-1906. Catedrático de Historia Universal y de España, fue separado de la Universidad como consecuencia de la denominada «Noche de San Daniel» y en solidaridad con D. Emilio Castelar, posteriormente, volvería a las aulas tras la revolución de 1868.

${ }_{5}$ Masonería española: páginas de su historia. Memoria leída en la Asamblea del Grande Oriente Español de 1915 por el Gran Maestre Miguel Morayta, Madrid 1915. 
refiere a actividades políticas concretas, ya que en la opinión que sostenemos no es posible establecer una correlación directa, lo que no quiere decir que algunos de sus miembros, como ya se ha indicado anteriormente, no desempeñaran actividades políticas de especial relevancia tanto en el Gobierno como en el Poder Legislativo, especialmente en el proceso constituyente. Si bien es cierto que su adscripción a diversas obediencias masónicas y fuerzas políticas dispares implicaban necesariamente actitudes políticas diferenciadas, lo que no obsta, para que los principios y valores de la Masonería universal tuvieran influencia en el pensamiento y actuación de los políticos pertenecientes a la Orden, ya que lo contrario significaría negar que los principios adquiridos en la orden iniciática no tuvieran su reflejo en el comportamiento privado de sus miembros, entre los que indudablemente estaban inmersas sus actividades políticas y afirmar lo contrario sería negar el valor y carácter de formación y perfección que corresponde a toda orden iniciática.

A este respecto, debemos centrarnos en dos aspectos: Influencia de la Masonería en la conformación del Primer Estado de Derecho o Primer Estado Constitucional y la significación histórica de la Segunda República.

a) Influencia de la Masonería en la conformación del Primer Estado de Derecho o Primer Estado Constitucional:

En este caso, nuestra referencia parece obligada a pesar del desfase histórico de siglo y medio entre la emergencia de los primeros textos constitucionales y la Constitución republicana de 1931.

Establecido el principio de que no puede destacarse actuación alguna de la institución masónica en la conformación práctica del Estado de Derecho, ello no debe inducirnos a considerar que en el mundo de las ideas no se produjera una clara influencia de la masonería en la sociedad civil y como consecuencia de ello se reflejara en la legislación pública y en las medidas de Gobierno ${ }^{6}$.

Podemos señalar entre las aportaciones de la masonería en este periodo los siguientes aspectos:

- La igualdad.

- Libertad de pensamiento.

- Libertad de conciencia.

- Libertad de expresión.

- Libertad de asociación.

- Libertad religiosa.

- El pluralismo.

- Concepción democrática o de participación.

6 Cayetano NúÑEz RIVERo, «Masonería y Estado de Derecho», en La masonería abre sus puertas (Ed. Atanor, 2012), 201-244. 
En suma se trata de principios que se incorporarán como valores fundamentales al Estado de Derecho y que serán proclamados en los textos constitucionales desde el Primer Estado Liberal; puede sostenerse, que estos principios ya estaban difundidos en la sociedad norteamericana y europea de la época, al menos, algunos de ellos, pudiendo resaltarse otros que no son específicamente provenientes de la masonería, como el concepto de «libertad personal», sin embargo, corresponde a la masonería la sistematización de los mismos y sobre todo el ponerlos en la práctica y proclamarlo en sus textos internos, además de contribuir poderosamente a su difusión, hasta convertirlos en categorías universales. En todo caso, podemos comprobar cómo dichos conceptos formulados en el seno de la institución masónica se trasladan a los textos constitucionales del primer Estado de Derecho y sobre todo, de qué manera podemos concluir que su promulgación en las Constituciones del mismo se derivan directamente de los postulados de las logias masónicas. Máxime, si tenemos en cuenta que aspectos como la libertad de conciencia y de expresión, así como de imprenta eran defendidos igualmente por los filósofos ilustrados del siglo XVIII; sobre este punto, cabe destacar que los filósofos que más se distinguirán en la defensa de estos valores son reconocidos como francmasones, tal es el caso de Montesquieu ${ }^{7}$ y Voltaire ${ }^{8}$, por mencionar sólo a los más representativos. En todo caso, hay un punto en el que es totalmente perceptible la influencia de la masonería en la conformación de los principios del Estado de Derecho, pues no existe precedente alguno de ello fuera de la institución masónica, tal es el caso de la libertad religiosa, plasmada posteriormente en los textos constitucionales más representativos del Estado Constitucional. Tampoco puede negarse la participación de numerosos masones en los procesos revolucionarios que dieron lugar a la caída del Antiguo Régimen, valga como ejemplo al respecto que en los Estados Unidos de Norteamérica, en la Declaración de Independencia de los Estados Unidos de Norteamérica, de cincuenta y seis (56) firmantes, existe constancia clara de que ocho (8) de ellos eran masones y sobre siete (7) más existen fundadas pruebas de su vinculación con la Orden, lo que representa más de la cuarta parte de los

${ }^{7}$ Charles de Secondat, fue un miembro muy activo de la Orden, especialmente hasta 1737; iniciado en 1730 en la Logia «Horn» de Londres; frecuentó con gran asiduidad las logias «Aubigny» y «Buci» en París; en sus obras no existen alusiones concretas a la masonería, aunque sí de la defensa de sus postulados coincidentes con el Estado de Derecho.

${ }^{8}$ El ingreso de Francisco María Arquet, Voltaire se produjo en la Logia «Las nueve hermanas» de París; su iniciación en la masonería fue tardía, el 7 de febrero de 1778 y próxima a su muerte. 
firmantes de tan importante documento. En términos similares podemos referirnos a los firmantes de la Constitución norteamericana de 1787, donde de un total de cuarenta firmantes (40), existe constancia de quince (15) masones, así como de trece (13) más existen fundadas pruebas de su vinculación con la masonería, lo que representa un setenta por ciento (70) del total de constituyentes. Referencias similares pueden hacerse de los mandos del ejército independentista, en el que la mayor parte de los mismos pertenecían a las denominadas logias militares. La posible influencia de la masonería también se percibe en muchos aspectos de carácter simbólico, tal como que la «piedra angular» del edificio del Capitolio, la colocó la Gran Casa masónica de Maryland; así mismo, aunque en un periodo posterior, en la propia moneda norteamericana se perciben claramente símbolos utilizados por la masonería, como la invocación a Dios «IN GOOD WE TRUST», o la pirámide en el reverso con el ojo que «todo lo ve», así como los correspondientes escalones y la existencia de una estrella de David de seis puntas, dispuestas en triángulo, con los correspondientes vértices simbolizando lo material y lo espiritual. Respecto a Francia, debemos indicar que al igual que en el caso norteamericano, las logias masónicas en Francia eran muy numerosas; Poco antes de la revolución existen en toda Francia 629 logias, de ellas 63 en el mismo París, adscritas al Gran Oriente, mientras que las logias del Oriente ascienden a 376. El número de francmasones en ese momento era superior a los 75.000 en Francia. Importantes personajes de la revolución o que participaron en la ideología que dio lugar a la misma eran masones (Montesquieu, ya indicado anteriormente,Saint Just, Desmoulins, Hebert, Danton, Marat, Chenie y otros muchos. El mismo himno de la revolución, «La Marsellesa», fue compuesto por un masón, Leconte de l'Isle, y fue cantada por primera vez en la Logia de los Caballeros Francos de Estrasburgo?. Por el contrario y como inciso que consideramos necesario aclarar, en nuestro primer proceso constituyente, las Cortes de Cádiz, a pesar de la existencia en su seno de diversos masones, algunos de gran prestigio como Alcalá Galiano o el propio ponente de la Constitución Agustín de Argüelles, no se percibe dicha influencia masónica, o no de forma tan diáfana ${ }^{10}$, como demuestra la proclamación de Estado confesional católico excluyente que se hace en el texto de $1812^{11}$.

${ }^{9}$ Cayetano NúÑEZ Rivero, ob. ant. cit.

10 J. M. Cayetano NúÑEz Rivero, El Estado Laico. La iglesia católica y el Estado Constitucional. El caso español (Ed. Endymion, 2011): 57-135.

${ }^{11}$ Debe recordarse la vigencia del decreto de 1751 de Fernando VI, referente a la persecución de la masonería, que sigue las directrices del Papado al respecto, así como la 
Establecida la posible correlación entre los valores y principios de la masonería y los postulados del primer Estado de Derecho, no puede decirse lo mismo respecto a la conformación del Estado Social y Democrático de Derecho, que es el que se va a empezar a desarrollar en el primer tercio del siglo Xx y en el que se encuadraría la Segunda República Española, ya que si para el primer Estado Constitucional es fácil percibir la influencia en los derechos y libertades individuales proclamados en los primeros textos constitucionales, no ocurre lo mismo en lo referente a los de carácter social y económico y al intervencionismo estatal, propio del Estado Social y Democrático de Derecho.

b) Significación histórica de la Segunda República española y desarrollo de la misma hasta 1939.

Sin embargo, respecto al caso español en 1931, hay algunos matices que es preciso resaltar, y es que la proclamación del Estado Social y Democrático de Derecho del texto de 1931, se lleva a cabo en un país donde la Revolución burguesa y el Estado Liberal no habían triunfado plenamente, quedando todavía conflictos inacabados por resolver propios del Antiguo Régimen, tal es el caso de la separación de la Iglesia y el Estado, la libertad de conciencia, de religión, de educación pública, y otros derivados de ellos, como el control del registro civil, secularización de cementerios, matrimonio civil etc.

De esta forma, el régimen republicano deberá afrontar no sólo los propios de la conformación de un Estado Social y Democrático de Derecho, sino también los del Estado Liberal que el constitucionalismo europeo y americano habían resuelto siglo y medio antes. Este problema no se resolverá con la proclamación de la Constitución de 1931, sino que tendrá un trágico desenlace en guerra civil de 1936 a 1939.

Es por ello, que en el proceso constituyente de 1931 los valores y principios masónicos enunciados anteriormente, que tuvieron reflejo en el constitucionalismo liberal de la época, tendrán vigencia a la hora de redactar el texto constitucional, aunque debe indicarse, que en este caso su procedencia no era directa, sino a través de los textos constitucionales existentes en los diferentes Estados de Derecho existentes.

Real Orden del 19 de enero de 1812, dada por el Consejo de Regencia, en cuya argumentación insisten en las condenas de la Iglesia Católica sobre la orden masónica. Sobre este punto no debe olvidarse la confusión entre la esfera pública y la religiosa que se produce en la España del Antiguo Régimen. 


\section{LA MASONERÍA, ¿SUJETO ACTIVO O PASIVO DE LAS LEYES REPUBLICANAS?}

El Pacto de San Sebastián de 17 de agosto de 1930, a la que concurrieron representantes de las más importantes fuerzas políticas y personajes de la oposición al sistema monárquico ${ }^{12}$,entre las que es fácil destacar una nutrida participación de masones, se aprobó el derrocamiento de la Monarquía, sentando las bases y principios de lo que sería el régimen republicano, entre los que se incluía una profunda descentralización territorial y el Estado Laico.

Es por ello, que incluso antes de iniciarse el proceso constituyente, el Gobierno Provisional de la República empezará a adoptar medidas tendentes a separar las actividades públicas de las correspondientes a la Iglesia, afirmando la libertad de conciencia de los ciudadanos, lo que ya se proclama en un Decreto de 15 de abril, «El Gobierno provisional hace pública su decisión de respetar de manera plena la conciencia individual mediante la libertad de creencias y cultos, sin que el Estado en momento alguno pueda pedir al ciudadano revelación de sus convicciones religiosas» ${ }^{13}$; junto a esta proclamación inicial, se producirán otros decretos, órdenes y circulares tendentes a hacer efectiva la separación entre el Estado y la Iglesia, tal como la orden dada a los Gobernadores Civiles el 17 de abril, para que no tuvieran presencia oficial en las ceremonias religiosas, ya que «las autoridades gubernativas han de ser totalmente neutrales en la esfera religiosa», la circular del Ministerio de la Guerra dos días después, mediante la que se eliminaba la obligación de asistir a misa en los cuarteles, y la prohibición de que hubiera representación militar en las procesiones; así mismo, el 23 de abril se derogaba el artículo 29 del Reglamento de prisiones, referente a la asistencia de los internos a los actos religiosos. Mediante decreto del 5 de mayo se modificaba la composición del Consejo de Instrucción Pública, extinguiendo la consejería de los prelados.

12 A la citada reunión asistieron. Alianza Republicana: Alejandro Lerroux, del Partido Republicano Radical, Manuel Azaña, de Acción Republicana; Partido Radical-Socialista: Marcelino Domingo, Álvaro de Albornoz y Ángel Galarza; Derecha Liberal Republicana: Niceto Alcalá-Zamora y Miguel Maura; Acción Catalana: Manuel Carrasco Formiguera; Acción Republicana de Cataluña: Matías Mallol Bosch; Estat Català: Jaume Aiguader; Federación Republicana Gallega: Santiago Casares Quiroga; del partido socialista, aunque a título particular, asistieron: Indalecio Prieto y Fernando de los Ríos; también a título particular acudió Felipe Sánchez Román y Eduardo Ortega y Gasset; la reunión contó con importantes adhesiones escritas como la del Dr. Gregorio Marañón, así como con diversas aquiescencias militares.

${ }_{13}$ Punto 4. Gaceta de Madrid, 15 de abril de 1931.Se completaría mediante Decreto de 22 de mayo, en el que se prohibía tanto a las autoridades civiles como militares preguntar sobre las creencias religiosas de quienes compareciesen ante ellos o les estuvieran subordinados. 
En el proceso constituyente se pondría de manifiesto desde el principio la voluntad de los representantes de la soberanía popular de conformar un Estado laico ${ }^{14}$.

La primera reacción oficial de la jerarquía católica española es la denominada Carta colectiva de los Metropolitanos españoles ${ }^{15}$, redactada en Roma $^{16}$, y dirigida al Jefe de Gobierno español el 3 de junio, en la que tras enumerar las medidas adoptadas por el Gobierno Provisional de la República y las anunciadas ${ }^{17}$, así como en previsión del posible contenido del

${ }^{14}$ En todo caso, debe resaltarse, que el proceso constituyente se inicia en un momento de gran agitación respecto al tratamiento de la libertad religiosa, pues por una parte, el concepto de laicidad adquiere pronto en la prensa de sectores de la izquierda un tono anticlerical, mientras que en la católica más conservadora, se hace una defensa a ultranza de la integridad católica española, que en ocasiones incide en el golpismo contra el régimen republicano, valga como ejemplo, el artículo «Agotada ya la paciencia, debe ocupar su puesto la resistencia viril» publicado en la Gaceta del Norte el 15 de agosto «(...) pero la prudencia hoy deja ya de aconsejar el uso de la paciencia y manda empuñar las armas de la oposición varonil a la tremenda agresión de que está siendo víctima la religión católica de nuestro pueblo... ni podemos estar dispuestos a soportar estas nuevas violaciones sustanciales, porque nos lo prohibe la conciencia, porque nos lo prohíbe nuestra propia dignidad de cristianos (...)». El Gobierno republicano procedió a suspender en estas fechas la publicación de varios periódicos, especialmente en el País Vasco y Navarra, algunos de ellos de carácter nacionalista, como es el de referencia y Euzkadi.

${ }^{15}$ La Conferencia de Metropolitanos es una institución nacida en los últimos años del sistema de la Restauración (1921), que se consolida durante la Dictadura de Primo de Rivera (Reglamento de 1929); responde a una iniciativa vaticana, similar a otras acaecidas en el continente europeo, con el fin de impulsar una mayor presencia de la Iglesia en la sociedad, así como de constituir una sola voz en cada Estado de la jerarquía católica en el mismo; no obstante, debe destacarse que según el citado Reglamento, para la ejecución de sus acuerdos precisaba de la autorización de Roma, lo que en la práctica, otorgaba una gran esfera de poder al Nuncio apostólico en España. Es el antecedente directo de la Conferencia Episcopal Española. Sobre su formación y desarrollo, véase Santiago CASAS RABASA, «La agenda de la Conferencia de Metropolitanos españoles» en Católicos entre dos guerras. La religión de España en los años 20 y 30, ed. Por J. Aurell PÉrez LóPez, (Madrid: Biblioteca Nueva, 2006).

${ }^{16}$ Sobre las relaciones Iglesia-Estado en el periodo constituyente de la Segunda república, véase. Cayetano NúÑEZ RIVERO, «La configuración constitucional del Estado Laico en la Segunda República española» en Rev. Laicidad y Libertades. Escritos jurídicos, n. ${ }^{\circ} 13$ (2013): 201-241.

17 Los puntos citados por la jerarquía eclesiástica eran: a) Anuncio oficial de secularización de cementerios; b) Separación de la Iglesia y del Estado; c) Prohibición a las autoridades gubernativas y del ejército de participar oficialmente en actos religiosos; d) Supresión de las cuatro Órdenes Militares; e)Privación de los derechos civiles a la Confederación Nacional Católica Agraria por el hecho de denominarse católica; f) Privación a la Iglesia de intervenir en los Consejos de Instrucción; g) Supresión de honores militares al Santísimo Sacramento a su paso por las calles; h) Supresión de la obligatoriedad de la 
texto constitucional al respecto, manifiesta su condena de las mismas, exigiendo su derogación y que se respetaran las prerrogativas de la Iglesia, argumentando que en lo referente a «los derechos de la Iglesia en España», debía obrarse de acuerdo con la Santa Sede ${ }^{18}$.

La Constitución de 1931promulga en su artículo 3. ${ }^{\mathrm{a}}$ el carácter laico del Estado, «El Estado español no tiene religión oficial», remitiendo a la totalidad de confesiones religiosas al concepto de Asociaciones y sujetas a una ley especial $^{19}$. Igualmente el texto constitucional proclama la libertad de conciencia y la libertad religiosa, garantizando la práctica de cualquier religión, sin más limitación que «el respeto debido a las exigencias de la moral pública $\rangle^{20}$, de esta forma, se equiparaba la religión católica a las restantes confesiones religiosas existentes en el Estado, reduciendo sus actividades al ámbito privado, ya que las manifestaciones públicas del culto debían ser autorizadas por el Gobierno ${ }^{21}$, así mismo, nadie podía ser «compelido a declarar oficialmente sus creencias religiosas $\rangle^{22}$, lo que se completará respecto a los funcionarios públicos en el artículo $41^{23}$, «No se podrá molestar ni perseguir a ningún funcionario público por sus opiniones políticas, sociales o religiosas», expresión a la que no obstante, se incluiría una cláusula de carácter restrictiva, en cuanto que declaraba como no elegibles para la Presidencia de la República «los eclesiásticos, los ministros de las varias confesiones y los religiosos profesos» ${ }^{24}$, prescripción que se hacía extensiva a la figura del Presidente del Gobierno ${ }^{25}$ y cuyos antecedentes pueden situarse en la Constitución mexicana de 1917, texto que así mismo influirá, en la opinión que sostenemos, en otros aspectos sobre el tratamiento religioso en la Constitución republicana española, especialmente en el referente a las Órdenes religiosas, en el que se aprecian unas disposiciones de carácter más radical que en el resto del texto citado.

El Estado ponía fin al sostenimiento del clero y culto, imperante desde la constitución de 1837, «El Estado, las regiones, las provincias y los Municipios,

enseñanza religiosa en las escuelas primarias y en las superiores; i) Prohibición del crucifijo en las escuelas; j) Libertad de cultos; k) Intervención del Estado en el tesoro artístico de la Iglesia; 1) Infracción de la inmunidad personal eclesiástica, a lo que añadía la acusación correspondiente por la quema de iglesias y conventos acaecida unos días antes.

18 Sobre este punto se invocaba el Concordato entre el Estado Español y la Santa Sede de 1851.
19 Artículo 26.C.E.1931.
20 Artículo 27, párrafo primero.
21 Artículo 27, párrafo tercero.
22 Artículo 27, párrafo cuarto.
23 Artículo 41, párrafo dos.
24 Artículo 70.
25 Artículo 87. 
no mantendrán, favorecerán, ni auxiliarán económicamente a las Iglesias, Asociaciones e Instituciones religiosas» ${ }^{26}$, así mismo, proclamaba la total extinción en un plazo máximo de dos años del presupuesto dedicado al clero ${ }^{27}$, «Una ley especial regulará la total extinción, en un plazo máximo de dos años, del presupuesto del clero» ${ }^{28}$,

Así mismo, sometía a la actividad tributaria a los bienes de la Iglesia ${ }^{29}$, bien de forma indirecta, «Toda la riqueza del país, sea quien fuere su dueño, está subordinada a los intereses de la economía nacional y afecta al sostenimiento de las cargas públicas, con arreglo a la Constitución y a las leyes ${ }^{30}$, o con un carácter directo, como acontece respecto a la referencia que hace a las Órdenes religiosas «sumisión a todas las leyes tributarias del país $\rangle^{31}$; impedía igualmente que las Órdenes religiosas pudiesen adquirir o conservar bienes, o tener propiedad diferente a su vivienda o no destinada al cumplimento directo de sus fines privativos ${ }^{32}$, prohibiendo igualmente que dichas Órdenes pudieran «ejercer la industria, el comercio o la enseñanza» ${ }^{33}$. Así mismo, se obligaba a las Órdenes a «rendir anualmente cuentas al Estado de la inversión de sus bienes en relación con los fines de la Asociación» ${ }^{34}$.

Otros preceptos constitucionales de gran importancia para la Iglesia Católica fueron la secularización de los cementerios ${ }^{35}$ y lo referente a las Órdenes religiosas, proclamado igualmente en el Título III del texto constitucional; respecto al primer caso, significaba privar de un importante

26 Artículo 26, párrafo segundo.

$27 \mathrm{Al}$ advenimiento de la República, el 78\% del clero percibía menos de 2.000 pesetas anuales, el $15 \%$ cobraba las 2.000 , y sólo el $6 \%$ alcanzaba una cifra superior, incluyendo en este grupo a los Obispos, que percibían de 26.500 a 45.000 pesetas. En Víctor Manuel ArBelOA, «Iglesia y república: diálogo imposible», Historia 16, n. ${ }^{\circ} 60$ (1981): 76.

28 Artículo 26, párrafo tercero. Aprobado el texto constitucional, el Gobierno mantuvo hasta 1933 la cantidad de 525 pesetas anuales para los 9.222 párrocos mayores de de cincuenta años. En Arbeloa, ob. ant. cit. 77.

${ }^{29}$ A ello debe unirse la proclamación del artículo 45, referente a la posible intervención estatal en el rico patrimonio artístico de la Iglesia. «Toda la riqueza artística e histórica del país, sea quien fuere su dueño, constituye tesoro cultural de la Nación y estará bajo la salvaguardia del Estado, que podrá prohibir su exportación y enajenación y decretar las expropiaciones legales que estimare oportunas para su defensa. El Estado organizará un registro de la riqueza artística e histórica, asegurará su celosa custodia y atenderá a su perfecta conservación».

30 Artículo 44, párrafo primero.

31 Artículo 26, párrafo quinto, 5. .

32 Artículo 26, párrafo quinto, $3 .^{\mathrm{a}}$.

33 Artículo 26, párrafo quinto, $4 .^{\mathrm{a}}$.

34 Artículo 26, párrafo quinto, 6. ${ }^{\circ}$.

35 Artículo 27, párrafo segundo. 
resorte de poder al clero, especialmente en el ámbito local, de tal forma, que se ponía fin a un residuo del Antiguo Régimen, que hasta el advenimiento del Estado Constitucional había depositado en la institución eclesiástica el registro de defunciones del Estado, como también lo había hecho con los bautizos como registro de nacimientos y acceso a la nacionalidad de la ciudadanía, constituyendo siempre un punto de conflicto entre la Iglesia y los sectores liberales, valga destacar, que aunque los efectos legales no eran los mismos que en el pasado, el control eclesiástico sobre los cementerios implicaba una forma de discriminación sobre los sectores no católicos de la sociedad española.

Respecto al segundo caso, referente a las Órdenes religiosas, la Constitución proclama dos medidas:

La supresión de las Órdenes religiosas que tuvieran un cuarto voto de obediencia "Quedan disueltas aquellas Órdenes religiosas que estatutariamente impongan, además de los tres votos canónicos, otro de especial obediencia a autoridad distinta de la legítima del Estado» ${ }^{36}$. La supresión de estas órdenes implicaba que los bienes de las mismas serían nacionalizados y «afectos a fines benéficos y docentes» ${ }^{37}$.

Sometimiento de las restantes Órdenes religiosas al Estado, mediante una Ley, que impondría unas condiciones claramente restrictivas ${ }^{38}$ :

1. ${ }^{\text {a }}$ Disolución de las que por sus actividades constituyan un peligro para la seguridad del Estado.

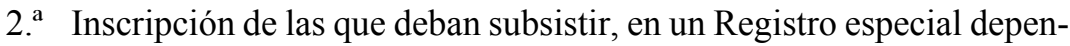
diente del Ministerio de Justicia.

3. Incapacidad de adquirir y conservar, por sí o por persona interpuesta, más bienes que los que, previa justificación, se destinen a su vivienda o al cumplimiento directo de sus fines privativos.

4. ${ }^{\mathrm{a}}$ Prohibición de ejercer la industria, el comercio o la enseñanza.

5. ${ }^{a}$ Sumisión a todas las leyes tributarias del país.

6. ${ }^{a} \quad$ Obligación de rendir anualmente cuentas al Estado de la inversión de sus bienes en relación con los fines de la Asociación.

Los bienes de las Órdenes religiosas podrán ser nacionalizados.

${ }^{36}$ La medida iba dirigida al voto de obediencia al Papa, que manifestaban los miembros de determinadas órdenes religiosas, especialmente la Compañía de Jesús. Esta medida tiene precedentes en el constitucionalismo europeo, especialmente el francés, en los primeros años de la conformación del Estado de Derecho, respondiendo en ese caso a los intentos de culminar una política regalista no sujeta a la autoridad directa del Vaticano, sino vinculada a los intereses nacionales.

37 Artículo 26, párrafo cuarto.

38 Artículo 26, párrafo quinto. 
Sobre este punto, debe destacarse, que no parece propio de un texto constitucional que proclama el Estado Social y Democrático de Derecho, el tercero en la historia de esta tipología constitucional, que trate de una forma tan pormenorizada un aspecto que podría considerarse de carácter marginal, como es el tema de las Órdenes regulares, más propio de proclamaciones del Primer Estado de Derecho, que puso fin al Antiguo Régimen, ya que con una simple remisión a futura ley de desarrollo hubiera bastado para el cumplimiento de los fines previstos, máxime si tenemos en cuenta que el texto de 1931, no puede catalogarse como extenso, aunque sí completo, y más bien debe encuadrarse como una constitución de tipo medio. Sin embargo, la extensión y la ubicación de estas proclamaciones en sitio tan significativo como es el correspondiente a lo que hoy en Derecho Constitucional llamamos Derechos Fundamentales, como es el Capítulo I «Garantías individuales y políticas» del Título III «Derechos y deberes de los españoles», nos advierte de la importancia que el constituyente otorgaba al tema religioso, y es, que ha de tenerse presente, que el proceso constituyente republicano de 1931, no es una mera reforma constitucional llevada a cabo desde un Estado Liberal Democrático, que se transforma en Estado Social y Democrático de Derecho, incorporando a su texto los derechos económicos y sociales, sino que es consecuencia de un largo proceso de ruptura con un sistema monárquico, cuyos últimos diez años habían sido de carácter dictatorial, y que contaba con unos antecedentes constitucionales que desde su origen, no habían podido afrontar la proclamación, no ya de la separación de la Iglesia y el Estado, como acaeciera en los primeros textos constitucionales de otros Estados, sino de la simple delimitación de los ámbitos públicos y eclesiásticos; de esta forma, la Constitución de 1931, así como todo el proceso revolucionario inherente a la misma, se nos presenta no sólo como un texto que intenta conformar un Estado Social y Democrático de Derecho, sino como una Constitución, que a la vez, debe sentar los principios del Primer Estado de Derecho y la evolución del mismo ocurrida en otros Estados durante más de siglo y medio, a lo que debemos añadir una cierta concepción revolucionaria seguida por amplios sectores de la clase trabajadora, que ya no tiene como meta la consolidación del modelo constitucional clásico, respecto al cuál es rupturista, tras el proceso revolucionario de la Unión Soviética. Todo ello, implica que dichas medidas pudieran calificarse de anticlericales, pero en realidad, no eran más que consecuencia de que las mismas no habían sido proclamadas en el momento histórico pertinente, como acaeciera en Europa, donde tuvieron un desarrollo evolutivo sin grandes sobresaltos.

Uno de los temas en los que la Constitución republicana fue más innovadora, es en el ámbito de los Derechos de Familia, aspecto en el que se producirá una de las más importantes confrontaciones con la Iglesia Católica, ya 
que el texto de 1931, tras declarar la igualdad de derechos para ambos sexos y la igualdad de derechos para los hijos nacidos dentro y fuera del matrimonio ${ }^{39}$, proclama el derecho al divorcio, «y podrá disolverse (el matrimonio) por mutuo disenso o a petición de cualquiera de los cónyuges, con alegación en este caso de causa justa $\rangle^{40}$

La educación, pieza clave de la influencia de la Iglesia Católica en la sociedad española, será un aspecto fundamental en el tratamiento constitucional $^{41}$, que motivará airadas protestas en la jerarquía eclesiástica, como consecuencia del importante control que ésta tenía históricamente sobre la misma $^{42}$. La Constitución de 1931, proclama que «el servicio de la cultura es atribución esencial del Estado», incidiendo a continuación, que tal servicio se prestará «mediante instituciones educativas enlazadas por el sistema de la escuela unificada $»^{43}$, de esta forma, aunque no se imponga la exclusividad de la Escuela Pública, el Estado pasa a ejercer un estricto control sobre toda la enseñanza ${ }^{44}$, que pasa a ser gratuita y obligatoria ${ }^{45}$ (primaria) y que además debe ser laica «La enseñanza será laica, hará del trabajo el eje de su actividad metodológica se inspirará en ideales de solidaridad humana» ${ }^{46}$. Estos aspectos, unidos a la proclamación del artículo 26, que prohibía a las Órdenes

39 Artículo 43, párrafos tres y cuatro.

40 Artículo 43, párrafo primero.

${ }^{41}$ Puede destacarse, que el esfuerzo más importante que la II República realizó fue en educación. España contaba al advenimiento de la República con un 40\% de analfabetismo. Se llevó a cabo una considerable inversión a favor de la escolarización y la enseñanza pública, construyendo en 1931, 7000 escuelas y 6.500 más entre 1932-33, aumentando el número de alumnos de 70.876 en 1930, a 130.572 en 1934. Vid al respecto. Cayetano Núñez Rivero y Rosa Martínez Segarra, Historia Constitucional de España, (Madrid:Ed. Universitas, 1997), 213.

42 En el momento de la proclamación de la Segunda República, los colegios católicos englobaban a un tercio de los alumnos de enseñanza primaria y a casi un $80 \%$ de los de secundaria. Vid. José Luis ORELla MARTínEZ, «El Origen del primer catolicismo social español», (Tesis Doctoral, UNED, 2012).

43 Artículo 48, párrafo primero.

44 «La expedición de títulos académicos y profesionales corresponde exclusivamente al Estado, que establecerá las pruebas y requisitos necesarios para obtenerlos aun en los casos en que los certificados de estudios procedan de centros de enseñanza de las regiones autónomas. Una ley de Instrucción pública determinará la edad escolar para cada grado, la duración de los periodos de escolaridad, el contenido de los planes pedagógicos y las condiciones en que se podrá autorizar la enseñanza en los establecimientos privados». Artículo 49.

45 Artículo 48, párrafo dos; además mediante el párrafo cuatro del citado artículo, la República se comprometía a remover los obstáculos para el estudio de los más necesitados, de tal forma, que éste «...no se halle condicionado más que por la aptitud y la vocación».

46 Artículo 48, párrafo cinco. 
religiosas ejercer la enseñanza ${ }^{47}$, no sólo acababan con el predominio de la Iglesia en la enseñanza y la difusión generalizada de sus principios en ese ámbito, sino que en la práctica, casi la dejaba fuera de la enseñanza primaria y secundaria, no obstante, lo proclamado «Se reconoce a las Iglesias el derecho, sujeto a inspección del Estado, de enseñar sus respectivas doctrinas en sus propios establecimientos» ${ }^{48}$.

La proclamación del laicismo estatal fue uno de los temas más conflictivos en el proceso constituyente, pues si para los sectores de la derecha española representada en las Cortes, la separación de la Iglesia y el Estado significaba un ataque a la religión católica, a la que consideraba esencia principal del alma de la nación, para la izquierda era considerado tema irrenunciable dentro del proceso de transformación y modernización del Estado español, que se había iniciado con la sustitución de la forma monárquica de gobierno por la republicana, así como una antigua aspiración de las fuerzas progresistas españolas. Prueba del estado de ánimo al respecto de los constituyentes republicanos, son las palabras de Fernando de los Ríos que abrió el debate el 8 de octubre de 1931», en las que resume toda una aspiración histórica frustrada del pensamiento liberal español,

(...) Llegamos a esta hora, profunda para la historia española, nosotros los heterodoxos españoles, con el alma lacerada y llena de desgarrones y de cicatrices profundas, porque viene asi desde las honduras del siglo XVI; somos los hijos de los erasmistas, los hijos espirituales de aquellos cuya conciencia disidente individual fue estrangulada durante siglos. Venimos aqui con una flecha clavada en el corazón del alma, y esa flecha es el rencor que ha suscitado la Iglesia por haber vivido durante años confundida con la monarquía, haciéndonos constantemente objeto de las más hondas vejaciones, no ha respetado ni nuestras conciencias ni nuestro honor, nada. Incluso en la hora suprema de la muerte, nos ha separado de nuestros padres»;

Otras voces de la izquierda serán más radicales, tratando el tema desde un punto de vista estrictamente político y con un carácter de enfrentamiento,

«la Iglesia para mí es un instrumento de dominación política y económica y no es más que una sociedad mercantil, una sociedad anónima explotadora de Dios, de Cristo y de la Madre de Dios; y la Compañia de Jesús debería llamarse la Compañía mercantil de Jesús» ${ }^{49}$.

Otros sectores de la derecha presentes en las Cortes acabarán aceptando la separación de la Iglesia y el Estado, aunque manifestarán su oposición a la

${ }^{47}$ Artículo 26, base 4. ${ }^{\mathrm{a}}$.

48 Artículo 47, párrafo seis.

49 Ángel Semblancat y Salanova, de Izquierda Catalana. 
proclamación de Estado Laico por considerarlo representativo de un estado de beligerancia a la Iglesia, así Gil Robles manifestará ${ }^{50}$,

«el articulo 3 del proyecto o dictamen constitucional que establece «No hay religión del Estado», no indica neutralidad religiosa, sino una declaración de absoluto laicismo de Estado, que, como comunidad perfecta, debe velar por «bien supremo religioso». No obstante, indica, los católicos no tienen inconveniente en reconocer la separación entre ambas instituciones, siempre que «se reconozca la plena personalidad jurídica de la Iglesia, como sociedad perfecta independiente, que implica el respeto a sus fines privativos, a su régimen propio, a todas sus entidades jerárquicas y a la libre disposición de los medios necesarios para el cumplimiento de sus fines».

De esta forma, el Estado español optaba por el Estado Laico, entendido éste, como un Estado, que tras afirmar la libertad de conciencia, la religión dejaba de ser un hecho público, pasando exclusivamente a la esfera individual de los ciudadanos, al ámbito privado de los mismos, eliminándose el concepto de servicio público de los cultos. El modelo no era nuevo, ni bajo aspecto alguno puede considerarse como algo originario del constitucionalismo español, estaba ya proclamado en los primeros textos constitucionales del Primer Estado de Derecho, norteamericano y sobre todo francés ${ }^{51}$, modelo que es el que en realidad seguirán los constituyentes republicanos españoles. La diferencia con otros textos constitucionales no estriba en los conceptos manejados, que son los mismos, especialmente en el citado caso francés, más próximo a nuestro ámbito cultural, sino en la pormenorización que hace el texto sobre el tema, pero sobre este punto, como ya se ha indicado, sólo respondía a la ausencia de una mínima legislación previa, enorme diferencia con el citado precedente francés, así como a la importancia de las instituciones eclesiásticas en España, marcadamente diferente de cualquier otro país, acaso con la salvedad mexicana, que hubiera proclamado la separación de la Iglesia y el Estado Laico.

El desarrollo de la legislación referente a la separación de la Iglesia Estado y la consolidación de un Estado Laico previsto en la Constitución, se llevaría a cabo en un tiempo corto, comenzando en enero de $1932^{52}$

\footnotetext{
50 José María Gil-Robles y Quiñones, diputado agrario.

${ }^{51}$ Artículo 10 de la declaración de los Derechos del Hombre y del ciudadano y Ley de 1905.

52 A este respecto, podemos destacar las siguientes normas y disposiciones:

a) Ley de disolución de la Compañía de Jesús.

b) Ley del divorcio.

c) Decreto de secularización de los cementerios.

d) Orden de retirar los símbolos religiosos de los centros educativos oficiales.
} 
La respuesta de la Iglesia Católica ante la proclamación de Estado Laico no se hizo esperar, así será tanto el Papado, como el propio Episcopado español, que en una pastoral de $1 .^{\circ}$ de enero de $1932^{53}$, a los pocos días de la promulgación del texto constitucional manifiesta su opinión de rechazo al mismo y de hostilidad ante la nueva realidad de la separación de la Iglesia y el Estado. «Los principios y preceptos constitucionales en materia confesional no sólo no responden al mínimum de respeto a la libertad religiosa y de reconocimiento de los derechos esenciales de la Iglesia que hacían esperar el propio interés y dignidad del Estado, sino que, inspirados por un criterio sectario, representan una verdadera oposición agresiva, aún a aquellas mínimas exigencias».

En los escritos de la jerarquía católica española ya aparecen claras referencias a la masonería como responsable de lo que considera medidas anticlericales. Así en HORAS GRAVES (12-VII-1933). Isidro Gomá, el que luego será Primado de España, Comienza su escrito describiendo en su opinión la situación de la Iglesia en España y su evolución desde la proclamación de la República ${ }^{54}$, destacando la persecución «verdaderamente diabólica» de que es objeto y que no tiene parangón en la historia. A diferencia de los documentos anteriormente citados, en éste se exponen las causas, que en opinión de su autor son las responsables de la situación, distinguiendo al respecto Causas externas e internas.

Entre las primeras cita en prominente lugar a la Masonería, «La masonería quiere canonizar la impiedad, dice el gran obispo Torres y Bagés, y de hecho, cuando puede disponer del gobierno a su antojo, legaliza la pública impiedad y la impone a los ciudadanos como ideal de vida. Secta parricida, que intenta matar a Dios en el alma del pueblo, que sentirá siempre la paternidad del padre nuestro que estás en los cielos, del que la masonería, porque es hija y colaboradora de Satanás, es enemiga implacable».

e) Ley de Confesiones y Asociaciones Religiosas.

La Ley de Confesiones y Asociaciones Religiosas, denominada como Ley del Candado por sus detractores, puede considerarse la de carácter más radical contra el interés concreto de la Iglesia española, ya que no sólo afecta a los principios del Estado Laico, sino también a importantes aspectos materiales

${ }^{53}$ La carta fue firmada por los Obispos el 20 de diciembre de 1931. Véase El Debate, $1 .^{\circ}$ de enero de 1932.

${ }^{54}$ «Hemos pasado, en días, de la paz a la guerra abierta... desde la destrucción vandálica de nuestros templos al asedio por el hambre... De una situación de privilegio y de respeto se nos ha colocado en condición de inferioridad civil y social...En dos años se nos ha aislado como si fuera la Iglesia una institución dañina o antisocial... y después de habérsenos quitado el pan de cada día, se ha traspasado al Estado toda nuestra riqueza... No parece sino que el Señor haya querido que se realizase en su Iglesia la visión del Profeta. In angustia et vastitate opprmet te hostis tuus (Deut,28,53)». 
En segundo lugar como causa externa cita al «intelectualismo descarriado e incomprensivo», remontando sus orígenes en los tiempos modernos a los «famosos humanistas que prepararon la falsa reforma», así como a Voltaire y los colaboradores de la Enciclopedia, incluyendo en el mismo grupo a personajes como Viviani, Marx y Liebknecht, que han contribuido a conformar una ciencia atea, en la que la religión no tiene cabida. Cita igualmente, el ateísmo en política, en el que destaca dos grandes ramas: «el laicismo político y la secta socialista», sobre la primera manifiesta, que aunque no niega a Dios, lo relega al fuero de la conciencia individual y lo destierra de la sociedad, de donde se deriva la doctrina separatista de la Iglesia y del Estado, a la que considera «hijuela del protestantismo» ${ }^{55}$. Respecto al socialismo, al que considera más radical en sus principios políticos, manifiesta que,

«partiendo del concepto materialista de la vida y de la historia, la religión le sobra, mayormente la cristiana, que es adoración de Dios en espiritu y en verdad. Y cualesquiera que sean los matices y variantes que adopte el socialismo con respecto a la religión individual, coincide absolutamente con el laicismo político en orden a la religión».

Las críticas a la Masonería y al Estado de Derecho se recrudecerán durante el periodo de la contienda bélica, así lo hara el cardenal Plá y Deniel, Obispo de Salamanca, en su Carta Pastoral «Las dos ciudades» ${ }^{56}$, del 30 de septiembre de 1936, que puede considerarse como el más extenso y entusiasta defensor del levantamiento militar contra la República, al que en reiteradas ocasiones en el documento define como cruzada, y especialmente el Primado de España, Cardenal Gomá en sus escritos El caso de España» (folleto) de 23 de noviembre de $1936^{57}$; Carta Pastoral «El sentido cristiano

55 «Radicalmente, el error moderno de la separación absoluta de los dos poderes arranca del protestantismo. Desde el momento en que, según el principio de Lutero, la fe sola justifica, queda la religión relegada a un plano personal y reducida a negocio puramente individual. Es la tesis de Marx, que en este punto no ha hecho más que sacar las últimas consecuencias de la doctrina de Lutero, estableciendo una separación radical entre la religión y la sociedad y, por lo mismo, entre el poder político y la autoridad religiosa».

56 Emplea el concepto de las dos ciudades que manejara San Agustín y que con tanta profusión se ha prodigado en las encíclicas papales; en este caso, identifica la terrena con las fuerzas republicanas -la revolución- («El comunismo y el anarquismo-que identifica con los hijos de Caín-son la idolatría propia hasta llegar al desprecio, al odio a Dios Nuestro Señor») y la celeste con las fuerzas contrarias al régimen republicano (enfrente de ellos han florecido de manera insospechada el heroismo y el martirio, que, en amor exaltado a España y a Dios, ofrecen en sacrificio y holocausto la propia vida).

57 Editado en Pamplona. Versión íntegra de la segunda edición en Anastasio GranADos, El Cardenal Gomá. Primado de España (Madrid: Espasa Calpe, 1969): 318 a 329. 
español de la guerra» de 30 de enero de $1937^{58}$, en los que une el laicismo y lo que considera las fuerzas de la anti-España, la Masonería, a la que en esta ocasión une, de forma un tanto inusitada y sólo comprensible por la influencia nacional socialista de las tropas alemanas en el bando franquista, al pueblo judío ${ }^{59}$, así como a los soviéticos.

Como ya se ha indicado en anteriores referencias, la Masonería será objeto de ataque primordial de la Iglesia Católica española, ya que culpa a la misma de ejercer una influencia decisiva en la conformación del Estado Laico, separación de la Iglesia y el Estado y leyes republicanas que la misma considera anticlericales; su actitud no variará durante la Guerra Civil, periodo en el que insistirá en denunciar a la institución masónica, en convivencia con el régimen franquista, valga como ejemplo, la carta remitida por el secretario del Primado Luís Despujol al Obispo de Salamanca José María Bulart, el 14 de marzo de 1937, en la que pide junto a otros encargos «... documentos y alguna fotografia principalmente para probar la responsabilidad de la Masonería, indicando traslade dicha petición al Gobierno militar ${ }^{60}$, así como al Obispo de Burgos Juan Tusquets, que en el citado día le remite el siguiente texto: Mi querido Juan: Escriben de Roma (Revista la Festa de Roma) al Sr. Cardenal pidiendo alguna fotografía y documentación para probar la responsabilidad y la obra nefasta de la Masonería en esta lucha. Me encarga el Sr. Cardenal te lo diga para que con la máxima urgencia veas de mandar todos los datos que tu juzgues más útiles a este fin» ${ }^{61}$.

Así mismo, en el informe del 3 de marzo de 1937, que el Cardenal Gomá remite a la Santa Sede, en el que reproduce su conversación con Franco, respecto a la derogación de las Leyes Laicas de España, pone en boca del General «De la masonería no quiero que queden en España ni las raíces».

${ }^{58}$ Puede verse íntegro en Montero Moreno, Historia de la persecución religiosa en España 1936-1939 (Madrid: 1961) Biblioteca de autores cristianos, Vol. II (Madrid: 1956), 708 a 726.

${ }_{59}$ No es la única vez que el citado Cardenal hace referencias de carácter anti semita, valga recordar a este respecto el Segundo Informe que remite al Cardenal Pacelli acerca del movimiento cívico militar, el 4 de septiembre de 1936, en el que identifica al «organizador de la resistencia comunista de Madrid» al israelita ruso Newman, indicando igualmente, que detrás de la persecución a la Iglesia Católica en Barcelona, pudieran encontrarse el judaísmo, "Hay en esta ciudad un fuerte núcleo de judios, que alli se habian instalado al amparo de la ley española y por las persecuciones de otros países, y que coadyuvan a la acción de Moscú. Tal vez ello podría explicar el carácter de ensañamiento tan profundamente anticristiano contra todo lo de nuestra religión: sacerdotes, templos, sagradas instituciones». Archivo Gomá. Documentos de la Guerra Civil. Documento 1-39. Sección 1. ${ }^{\text {a }}$ Legajo A. Carpeta I. Documento 2.

${ }^{60}$ Documento 4-140. Sección 1. a . Legajo G. Carpeta III. Documento 27.

${ }^{61}$ Documento 4-140. Sección 1. a . Legajo G. Carpeta III. Documento SC. 
(Archivo Gomá.) Así mismo, en marzo del 37, el Cardenal Primado, en entrevista concedida al Berliner Lokal Anzeiger, ante la pregunta del periodista ¿Hay alguna relación entre la revolución mexicana y la española?, respondía: Sin duda; ambas han sido organizadas por la masonería internacional.

En este intento de involucrar a la Masonería tanto en los orígenes como en el desarrollo e la Guerra Civil, la Jerarquía Católica española, por medio de su Primado, el Cardenal Isidro Gomá, no duda en achacar la resistencia vasca al ejército franquista a la organización masónica, o al menos, plantear una duda razonable en su opinión, incluyendo en el caso al propio Presidente Aguirre al respecto, así en informe del 25 de abril de 1937, remitido al Cardenal Pacelli, Secretario de Estado del Vaticano, con motivo de la caída de Bilbao, y como consecuencia de haberse encontrado un mandil masónico en las dependencias del Hotel Carlton, donde estaba instalado el Gobierno de Euzkadi, manifiesta: «...se encontró un magnífico mandil con un banda primorosamente bordados, utensilios masónicos. Sin duda, por la calidad de los objetos, correspondian a un alto personaje afiliado a la masonería. Se atribuye su pertenencia al Sr. Aguirre o a alguno de los dirigentes vascos... Si se pudiese comprobar con la ficha correspondiente -que algún dirigente vasco pertenecía a la masonería- no se ha dado con la ficha correspondiente a las insignias -sería ello la clave para explicar un fenómeno que es casi humanamente inexplicable, como es la monstruosa conjunción vasco-comunista, el repudio de una paz que podía hacer en condiciones inmejorables, pactándola separadamente del Gobierno de Valencia, y una resistencia loca en que forzosamente debian hundirse, por varios lustros, la economía del rico país ${ }^{62}$.

Lo que podemos calificar de obsesión por la masonería por parte de la Iglesia Católica española, se nos revela incluso en la sospecha de que dicha organización pudiera estar infiltrada en el régimen surgido del 18 de julio, como prueba la carta del Primado de España al Cardenal Pacelli, remitida el 11 de diciembre de 1936, en cuyo anexo primero, Gomá expone respecto a la situación política de la postguerra, «De todas maneras puede asegurarse que, de no intervenir factores insospechados-uno de ellos podría ser la masonería, que forcejea por abrirse paso en la nueva organización-mejoraría muchísimo la situación política en un sentido de conservación y restauración de todos los valores de la tradición española. Digo incidentalmente, con respecto a la masonería, que registros hechos en los archivos de los dirigentes de izquierdas que han podido ser intervenidos por emisarios del Gobierno actual, han puesto en manos de éste toda la urdidumbre de la historia de la revolución española en estos últimos, y especialmente cuanto se

${ }^{62}$ En Sección 1. . Legajo Carpeta VIII. Documento 51. 
refiere a la preparación del movimiento revolucionario que el alzamiento militar hizo abortar ... $\rangle^{63}$. No obstante, debe destacarse que otros sectores de la Iglesia Católica críticos con el régimen militar, en este caso franceses e influenciados por el clero catalán separatista, pertenecientes al Instituto Católico de París, sembraron la misma duda sobre la adscripción masónica de ciertos sectores del estamento militar, valga como ejemplo al respecto, el artículo «Guerre en Espagne», publicado en la Revue de Paris el 1 de octubre de 1936.

Los ataques de la Jerarquía Católica española a la Masonería no finalizarán con la Guerra Civil, valga como ejemplo, que en octubre de 1943 el Cardenal Segura, a la sazón cabeza de la Diócesis de Sevilla, en Pastoral, ampliamente difundida por la Prensa de la época (véase ABC Sevilla, 24 de octubre de 1943) tras condenar el baile y la ola de concupiscencia que invadía la vida española acusaba a la Masonería de no cejar en sus asechanzas incitando el relajo que lleva a la más impúdica perversión de la mujer, no desdeñando modo alguno de socavar la pureza en el mundo.

Sobre la actitud de General Franco y la Masonería, cabe destacar como se indica en la nota precedente que la misma en España será destruida, no ahorrando a tal fin, todos los medios represivos posibles. A este respecto, cabe destacar que el General Franco no cejó de manifestar críticas a la Masonería, siempre que tuvo ocasión durante todo el periodo de la guerra civil, acusando a esta organización de cuantos males debían combatirse en España. Impregnando siempre las mismas de un espíritu, a veces de carácter arcaico, «La unidad española, a tanta costa forjada, se quebró y despedazó al conjuro de fuerzas revolucionarias que se escudaban en un laicismo ateo y en la masonería judaizante.» (Invocación al Apóstol Santiago el 25 de julio de 1937) ${ }^{64}$.

Así, al margen de que desde los primeros días de la sublevación militar comenzó la persecución sistemática y exterminio de los masones y sus instituciones, valga como ejemplo primero la ocupación y fusilamiento por parte de miembros de la Falange de la Logia Tinerfe de Santa Cruz de Tenerife ${ }^{65}$. Son Igualmente representativos el fusilamiento treinta masones en los primeros días de la rebelión de la Logia Helmatia de Salamanca, treinta de la Constancia de Zaragoza, quince de la Zurbano de Logroño, siete de la Libertador de Burgos, siete de la Joaquín Costa de Huesca, diecisiete de la Hijos de la Viuda de Ceuta, veinticuatro de la Trafalgar de Algeciras, nueve de la Resu-

${ }^{63}$ En Sección 1. ${ }^{\text {a }}$ Legajo A. Carpeta I. Documento 11.S.N.

${ }^{64}$ Boletín Oficial del Obispado de Tuy (Septiembre de 1937).

${ }^{65}$ En el Archivo de Salamanca, en el Centro Documental de la Memoria Histórica (CDMH), dentro de la agrupación SE-Masonería-A se conserva, entre otros, documentación confiscada o relativa correspondencia, libros de actas, libros registro de correspondencia, listados nominales, reglamentos, etc. a la Logia Tinerfe). 
rrección de La Línea, tres de la Fiat Lux de La Línea. En Málaga lo fueron ochenta presos políticos, fusilados bajo la pena de ser masones ${ }^{66}$.

El periódico $\mathrm{ABC}$ del 23 de septiembre 1936 publica la siguiente noticia de Granada: ...se apoderaron de los ficheros de las dos logias masónicas que existian en la capital e hicieron prender a todos los masones. En camiones los trasladaron al vecino pueblo de Viznar, donde fusilaron a los venerables, $y$ después de tener encarcelados varios días a todos los demás los condujeron al campo y les obligaron a cavar sus propias sepulturas, tan pronto las terminaban eran muertos a tiros.

Aplicándose a la Masonería los Bandos y Órdenes de lo Generales y Junta de Defensa proclamados para la a represión de aquellos que se opusieran a la fuerzas sublevadas (General Mola Diario de Navarra. Pamplona: 19 de julio de 1936, portada (General Saliquet, Valladolid 19 de julio). Bando de 28 de julio de 1936, haciendo extensiva la declaración del Estado de Guerra a todo el territorio. (BO de la Junta de Defensa Nacional de España de 30/07/1936, n. ${ }^{\circ}$ 3), Sin embargo la primera normativa específicamente contra la masonería se producirá el 15 de septiembre de 1936, firmado por el propio General Franco.

Artículo 1. ${ }^{\circ}$. La francmasonería y otras asociaciones clandestinas son declaradas contrarias a la Ley (se refiere a rotarios y teósofos).

Todo activista que permanezca en ellas tras la publicación del presente Edicto será considerado como crimen de rebelión.

Artículo2. ${ }^{\circ}$. El cobro o pago de cotizaciones a favor de dichas asociaciones serán considerados como crimen de rebelión, sin perjuicio de la multa de 5000 pesetas que puede ser además impuesta por la Junta de Defensa Nacional.

Articulo 3.. . Toda pieza de identidad, recibos, correspondencias, emblemas, etc. deberán ser quemados por sus poseedores en los tres días siguientes a la publicación del presente Edicto; pasado este plazo, el descubrimiento de dichos objetos, sea en la persona de los interesados, sea en su casa, será considerado como crimen grave de desobediencia, sin perjuicio de la multa de 10.000 pesetas fijada por la Junta por este motivo.

Artículo $4 .^{\circ}$. Los escritos de propaganda relativos a las asociaciones en cuestión serán considerados incursos en el Artículo 7 del Decreto del 3 de Septiembre último y deberán ser destruidos en un plazo máximo de tres días por sus poseedores.

Artículo 5. . Los inmuebles pertenecientes a las susodichas asociaciones serán confiscados por mis representantes y aplicados al uso que ellos determinen. Las casas alquiladas serán igualmente evacuadas y puestas a disposición de sus propietarios respectivos.

${ }^{66}$ Véase al respecto Ramón VIÑAls I SOLER, El holocausto masónico en la España de Franco (Boletin n. ${ }^{\circ} 33$ del Archivo Nacional de Cataluña de la Generalidad de Cataluña, 2013). 
El 20 de abril de 1937 se creó la Oficina de Investigación y Propaganda anticomunista, OIPA, que tenía como fin «recoger, tanto en la zona ocupada como en las que se vayan ocupando, la mayor cantidad de pruebas de las actividades marxistas en España, así como en particular de las SOCIEDADES MASONICAS... con el fin de obtener antecedentes sobre las actuaciones de los enemigos del Estado, así en el interior como en el exterior, y suministrar datos útiles a todos los demás organismos encargados de su defensa... instándose encarecidamente a las autoridades militares y civiles su más decidido apoyo en el desempeño de tan importante misión».

Por Orden del 29 de mayo de 1937, se creó la Delegación de Asuntos Especiales, que incluía una sección masónica, cuyo fin era recoger la documentación referente a actividades de las sectas secretas, que dependía directamente del General Franco.

El 26 de abril de 1938, mediante Decreto (BOE de 27/04/1938, n. ${ }^{\circ}$ 553, pp. 6986-6987) se crea la Delegación del Estado para la Recuperación de Documentos. Sobre la actividad de este organismo es prueba el escrito que el Delegado Nacional de Servicios Especiales en Salamanca, con fecha de 25 de agosto de 1938, reportando sus actividades enviaba directamente al Jefe del Estado, comunicándole sus actividades respecto a la catalogación y clasificación de expedientes «...14.930 expedientes individuales y 26.148 fichas de masones, 1.300 libros de actas y de administración de Logias, 248 expedientes de asuntos importantes sobre actividades masónicas, 394 expedientes de Logias de España y 257 de extranjeras... y en cuanto a los servicios prestados dice... este Organismo ha expedido 235 informes al Ministerio de Defensa-Sección de Justicia, 336 informes a la Auditoria Militar de Marruecos, 364 informes a diversas Auditorias Militares, 16 informes a Juzgados Militares, 9 informes a otras Auditorias, 291 informes a diversas Comisiones Depuradoras, 244 informes a Autoridades civiles, amén de numerosos informes colectivos del personal de los Cuerpos de Ingenieros de Minas, Telégrafos, Teléfonos y Correos, Profesorado, Maestros, Cuerpo Diplomático y Consular, Marina, etc., haciéndose también diariamente una revisión en el fichero de todos cuantos nombres figuran en los nombramientos para cargos que aparecen en el BOE. El Archivo quedaría radicado en la ciudad de Salamanca, siendo conocido como «Sección Política Social», y gestionado por un equipo policial.

El 10 de diciembre de 1938, mediante Decreto (BOE de 20/12/1938), se acaba con el proceso de secularización de cementerios llevada a cabo por la República, proclamando en la misma que se eliminen los símbolos masónicos de los cementerios «que; ...todas las inscripciones o símbolos de carácter masónico, o que pudieran considerarse ofensivos para la Iglesia católica, sean destruidos y eliminados de todos los cementerios en un plazo de dos meses...» 
La represión de la Masonería se acentuaría todavía más mediante las leyes de 9 de febrero de 1939 (BOE.de 13/02/1939) «Ley de Responsabilidades Políticas» que tenía carácter retroactivo y la de 1 de marzo de 1940 (BOE de 2/03/1940), promulgada casi un año después de terminada la Guerra Civil, denominada "Ley de Represión de la MASONERIA y el Comunismo»; mediante la primera se consideraba como circunstancias agravantes, el haber obtenido de la MASONERIA algunos de los grados dieciocho a treinta y tres, ambos inclusive, y haber tomado parte en las Asambleas de la Asociación Masónica Internacional o similares, o en las Asambleas del Gran Oriente Español, de la Gran Logia Española o de otras cualesquiera organizaciones masónicas residentes en España... En la segunda y en su exposición de motivos se concreta una imagen de la Masonería muy próxima a la que el General Franco tenía de la institución (véase al respecto el libro «Masonería», publicado en Madrid en 1952 firmado por Jakim Boor, seudónimo de Franco, que no es otra que la manifestada por el sector más reaccionario y absolutista del pensamiento español desde Fernando VII. «...entre las primeras ocupa puesto más principal la MASONERIA a la que acusa de la pérdida del imperio colonial, las guerras civiles, ...las perturbaciones que aceleraron la caída de la monarquía...minaron la dictadura...manifestando... así como los crímenes de estado se descubre siempre la acción de la MASONERIA ... al levantarse en armas el pueblo español no cejan la MASONERIA ...proporcionan armas, simpatías y medios económicos a los opresores de la patria...son escasas y reducidas el alcance de las disposiciones legales para castigar y vencer estas maquinaciones... sin que ahora se pretenda establecer la normativa definitiva y total...se hace indispensable determinar la clasificación jurídica y sanciones que merecen los que todavia secundan la MASONERIA.

$\mathrm{Y}$ en el articulado se proclama: RIA ...

Articulo $1 .^{\circ}$....constituye figura de delito el pertenecer a la MASONE-

Articulo 2. ${ }^{\circ}$...sus bienes se declaran confiscados.

Artículo $4 .^{\circ} . .$. son MASONES todos los que han ingresado en la masonería y no han sido expulsados o no se han dado de baja...y no dejan de serlo aquellos a quienes la secta ha concedido... alejamiento de la misma.

Articulo 5. ${ }^{\circ} .$. los delitos de MASONERIA serán castigados con la pena de reclusión menor ...excepto circunstancias agravantes.

Articulo $6 .^{\circ}$....son circunstancias agravantes el haber obtenido alguno de los grados 18 al 33...el haber asistido a asambleas...o desempeñado cargo o comisión que acredite especial confianza de la secta...

Artículo $7 .^{\circ}$... quienes hayan pertenecido a la MASONERIA vienen obligados a formular ante el Gobierno una declaración de retractación en el plazo de dos meses... 
Artículo 8. ... las personas comprendidas en el Artículo anterior quedarán separadas definitivamente de cualquier cargo del Estado, Corporaciones públicas o oficiales, entidades subvencionadas, empresas concesionarias, gerencias y consejos de administración de empresas privadas, cargos de confianza, mando o dirección de las mismas decretándose además su inhabilitación perpetua para los referidos empleos y su confinamiento o expulsión...serán sometidos a procedimiento de sanción económica.

Así mismo, con el fin de se diera la mayor difusión posible de las sentencias que hubiera sobre la Masonería al amparo de la ley de Represión de la Masonería y el Comunismo de 1 de marzo de 1940, la Vicesecretaría de Educación Popular remite orden a los a los Jefes Provinciales de Prensa, a la que adjunta una larga lista de condenados por su pertenencia a esa institución, con las siguientes instrucciones: ... al publicar el extracto de las sentencias cada periódico podrá agregarles detalles en cuanto a la perniciosa actuación que mantuvieron en cada caso durante la pasada guerra en España y aun en los acontecimientos que prepararon el Movimiento Nacional. Coincidiendo con la publicación de las sentencias sería conveniente la publicación de comentarios y artículos señalando la influencia de la MASONERIA en los trabajos que precedieron a la formación del Frente Popular y aun a la proclamación de la República, así como las infiltraciones de la MASONERIA en la política general liberal-demócrata, que antecedió a las elecciones del 13 de abril. Todos estos comentarios y artículos deberán tener una orientación de tipo histórico, representar una condenación a la vista del singular perjuicio que a España han infringido los afiliados a la SECTA...

El 4 de Junio de 1940 de Junio de 1940 entra en vigor, (Decreto de 4 de junio de 1940) el Tribunal Especial para la Represión de la Masonería y el Comunismo,(TERMC), que hasta su extinción en 1963, fecha en la que sus actividades pasaron al Tribunal de Orden público (TOP), llevó a cabo 48.000 sumarios acabados ${ }^{67}$.

Por último, prueba del pensamiento obsesivo del General Franco sobre la masonería es que en su último discurso público celebrado en la madrileña Plaza de Oriente el 1 de octubre de 1975, ya visiblemente enfermo manifestaría: «...todo lo que en España se ha armado obedece a una conspiración masónica izquierdista en la clase política, en contubernio con la subversión comunista-terrorista en lo social, que si a nosotros nos honra, a ellos les envilece...» (ABC. Madrid, 2 de octubre de 1975).

${ }^{67}$ Véase al respecto María Teresa DíEz DE Los Ríos SAN JuAn, Documento «Fondos de la masonería en la Sección 'Guerra Civil' del Archivo Histórico Nacional de Salamanca» en La Masonería en la Historia de España. Actas del I Symposium de Metodología Aplicada la Historia de la Masonería española, (Zaragoza: 20-22 de junio de 1983. Diputación General de Aragón, Departamento de Cultura y Educación, 1985), 335-348. 


\section{A MODO DE CONCLUSIÓN}

La influencia de la masonería en la Segunda República española se deriva en primer lugar de los valores y principios masónicos que en cierta medida se trasladaron a los primeros textos constitucionales correspondientes al Primer Estado de Derecho, tales como la libertad de conciencia, religiosa, separación de las iglesias y el Estado etc, principios los últimos que no habían podido manifestarse de forma diáfana a lo largo del constitucionalismo español del siglo XIX, pero que deberá afrontar el régimen republicano, al mismo tiempo que proclama el Estado Social y Democrático de Derecho. La tardía inclusión de estos derechos y libertades en nuestro constitucionalismo y la necesidad de que su vigencia sea lo más rápida posible, hace parecer su proclamación rodeada de un cierto anticlericalismo, lo que posibilita un duro enfrentamiento entre la República y la jerarquía católica española, en virtud de que la legislación republicana, tanto en el texto constitucional como en las leyes de desarrollo significaban una clara merma del poder de la Iglesia Católica, en cuanto ésta, hasta ese momento gozaba de atribuciones en el Estado más propias del Antiguo Régimen que de un Estado de Derecho en el siglo Xx.

La presencia de numerosos miembros de la masonería en puestos de responsabilidad política, tanto en la esfera gubernamental como en la legislativa, a pesar del reducido número de miembros de la Orden en España, hace que se convierta en el centro del ataque de la jerarquía católica española como responsable de las denominadas normas anticlericales.

La guerra civil, definida por la Iglesia española como Cruzada, acentuará más este enfrentamiento, que será utilizado por el régimen militar para desde su concepción del Estado como de nacional-catolicismo, llevar a cabo una represión sin precedentes históricos contra la Masonería, que algunos han definido como de genocidio, ya que los masones fueron para el franquismo lo mismo que los judíos para el nacional-socialismo.

\section{TITLE: Freemasonry and the Spanish Second Republic (1931-1939)}

RESUMEN: Este trabajo se centra en la influencia de la masonería en la configuración y desarrollo de la Segunda República Española. Tras realizar algunas consideraciones metodológicas de principio, este articulo analiza la relación entre los valores y principios masónicos y los valores y principios republicanos para, a continuación, centrarse en la relación de la institución masónica con el Derecho positivo republicano.

PALABRAS CLAVE: II República, Masonería, Derecho Constitucional.

ABSTRACT: This paper focuses on the influence of Freemasonry in the configuration and development of the Second Spanish Republic. After some 
methodological considerations, this article analyzes the relationship between Masonic values and the republican principles and values and, subsequently, it then focuses on the relation of the Masonic institution with positive republican law.

KEY WORDS: II Republic, Freemasonry, Constitutional Law.

RECIBIDO: 29.03 .2015

ACEPTADO: 30.05 .2017 